\title{
EFFECT OF FORCED EXERCISE (TAP STRESS) ON DROSOPHILA MELANOGASTER AND EFFICACY OF ABHRAK BHASMA AS DIETARY SUPPLEMENT
}

\author{
RAMBHADUR P SUBEDI ${ }^{1 *}$, REKHA R VARTAK ${ }^{2}$, PURUSHOTTAM G KALE ${ }^{1}$
}

${ }^{1}$ Department of Biological Sciences, Ramniranjan Jhunjhunwala College, Ghatkopar, Mumbai - 400 086, Maharashtra, India. ${ }^{2}$ Department of Biology Olympiad Cell, Homi Bhabha Centre for Science Education-TIFR, Mankhurd, Mumbai - 400 088, Maharashtra, India.

Email: subedi229@gmail.com

Received: 21 August 2017, Revised and Accepted: 16 October 2017

ABSTRACT

Objective: Generation of reactive oxygen species and other oxidants as an outcome of aerobic respiration has been well documented. During boosted muscular activities/exercise, there is an increase in the rate of respiration and subsequent generation of oxidants; for which, organisms possess various defense systems. There is, however, paucity of reports on the effect of forced exercise in Drosophila melanogaster.

Methods: The present investigation reports a method for inducing forced exercise, the "tap stress," in D. melanogaster. This method takes advantage of the natural tendency of Drosophila flies to climb/fly upward in a cylindrical tube. Simplicity of assembly, ease of experimentation and cost effectiveness are some of the key advantages of this method. Tap stress has been assumed to manifest through the generation of oxidative stress, thus, parameters indicative of oxidative stress have been evaluated.

Results: The results indicate that tap stress induces oxidative stress mainly by influencing the non-catalytic components; total reduced glutathione (GSH), GSH: oxidized glutathione ratio, and free radical scavenging capacity. The catalytic components (superoxide dismutase, and catalase), on the contrary, remain largely unaffected. Abhrak bhasma (AB) influences total GSH content with an increase by about $38 \pm 21 \%$, while flies on control diet register a decrease in total GSH content by $34 \pm 7 \%$ during tap stress. Feeding flies on AB, specifically, show a prominent increase in the transcription levels of cap " $n$ " collar $C$, heat shock protein 70 and catalase genes ( $>1.5$ fold).

Conclusion: Overall, dietary supplement of $\mathrm{AB}$ and ascorbic acid benefits Drosophila flies in the management of oxidative stress induced through tap stress.

Keywords: Drosophila, Physical stress, Abhrak bhasma, Ascorbic acid.

(C) 2018 The Authors. Published by Innovare Academic Sciences Pvt Ltd. This is an open access article under the CC BY license (http://creativecommons. org/licenses/by/4. 0/) DOI: http://dx.doi.org/10.22159/ajpcr.2018.v11i1.22139

\section{INTRODUCTION}

Physical activity is an important aspect of survival in an organism. Moderate exercise at regular intervals has been associated with many health benefits [1]. However, intensive exercise leads to the production of reactive oxygen and other free radical species, at a rate which cannot be matched by the rate of their neutralization by antioxidant mechanisms [2]. This may cause a number of perturbations to cellular integrity, including modifications in deoxyribonucleic acid (DNA) [3]. Various methods have been developed for testing the effect of increased physical activity in mammalian model system [4], but there is a paucity of such methods in Drosophila melanogaster.

The antioxidant system of the organism, involving catalytic and noncatalytic components, is the key defense against oxidative stress $[5,6]$. The catalytic component mainly includes various enzymes that target free radicals in a substrate-specific manner. The non-catalytic components consist of various nonspecific reducing moieties in the cell, including certain vitamins and glutathione (GSH) system $[7,8]$. In addition, activation factors synthesized through the translation of Cap " $\mathrm{n}$ " collar C ( $\mathrm{cncC}$ ) and heat shock protein (hsp) genes help in managing the oxidative stress [9].

One of the simplest, yet effective, ways of boosting the antioxidant defenses of an organism is to supplement its food with natural or synthetic antioxidant compounds. In the recent decade, a plethora of natural antioxidants and their synthetic counterparts have been discovered with promising results $[10,11]$. These synthetic food supplements, however, may have some toxic effects on the organism $[12,13]$. Vitamins are the most investigated compounds among these antioxidants. Ascorbic acid (ASC) or Vitamin C has an intrinsic capacity to scavenge free radicals and its supplementation, at moderate amount, has been shown to positively affect the survival of an organism [14]. However, there still exists a conflicting view regarding the application of ASC as an antioxidant compound [15]. In recent times, traditional medicines have shown a promising scope in this regard and are gaining popularity [16]. Abhrak bhasma $(\mathrm{AB})$ is one such traditional medicine that has been used in the treatment of a wide range of diseases such as hepatitis, tuberculosis, asthma, plague, gastritis, and skin diseases [17]. AB is also considered as an excellent cell regenerator and as a nervine tonic, thus used in many rejuvenation formulations [17]. The quality and efficacy of $A B$ depend on the number of puta (cycle of incineration) it is processed through. AB that undergoes 1000 puta (referred as sahastra puti) is considered to be of the finest quality.

The present investigation explores an experimental design (tap stress) for inducing intensive physical activity/stress in Drosophila flies and subsequent study of stress effects on oxidative stress parameters. This study also explores the possibility of using ASC and AB as a diet supplement for ameliorating the effects of oxidative stress induced through tap stress.

\section{METHODS}

AB

Sahastra puti $\mathrm{AB}$ was procured from Dhootapapeshwar Ltd., among the leading manufacturers of ayurvedic medicines (Batch No.: P150300110). 


\section{Drosophila husbandry}

D. melanogaster (Canton S strain) flies were maintained on Corn Meal Agar medium at $26^{\circ} \mathrm{C}$ with $12 \mathrm{~h}$ light and $12 \mathrm{~h}$ dark cycle. The control flies were allowed to lay eggs on a medium containing $0 \% \mathrm{AB}, 0.1 \% \mathrm{AB}$, $0.5 \% \mathrm{AB}$, and $20 \mathrm{mM}$ ASC for $12 \mathrm{~h}$. After $12 \mathrm{~h}$ of egg-laying, the adults were removed, and the eggs were allowed to develop till they attained the age of 2 days of adult life. These flies were then subjected to tap stress.

\section{Drosophila tap stress}

\section{Design of the instrument}

The tapping instrument consists of a holding unit and a tapping unit (Fig. 1). The holding unit includes a test tube rack pivoted to two burette stands such as to allow a free rotation up to $360^{\circ}$. The "fly retainer unit" consists of broad, polypropylene tubes, with tapering base, fixed in inverted position in the test tube rack with elastic bands. The mouth of each fly retainer tube needs to be plugged with cotton after introducing the flies, and a small strip of adhesive tape be applied for preventing unplugging of the cotton plug during tapping process. The tapping unit consists of a "tapper" fixed to a rotary shaker with provision for speed adjustment.

\section{Exerting tap stress}

The experiments were carried out in four replicates in the laboratory maintained at $26^{\circ} \mathrm{C}$ and $12 \mathrm{~h}$ light/12 h dark cycle. In every set of experiment, 2 days old adult flies (males and females in equal numbers), raised from larvae maintained in nutrient mediums containing $0 \%$ $\mathrm{AB}, 0.1 \% \mathrm{AB}, 0.5 \% \mathrm{AB}$, and $20 \mathrm{mM} \mathrm{ASC}$ were segregated into control and test groups ( 80 flies in each group). Flies of both the groups were introduced into the fly retainer tubes using "Ram Aspire," an aspirator designed by the authors [17]. The tubes containing only the flies of the test group were fitted to the tap instrument. Tapping was given to the flies of the test group by adjusting shaker at the speed that exerted 156 taps/min for $90 \mathrm{~min}$. This number and duration were decided on the basis of the results of pilot experiments, wherein different number and duration of taps were used. The rest period of $30 \mathrm{~s}$ was also included at the end of every $10 \mathrm{~min}$. The flies from control groups were kept in fly retainer tubes idle for $90 \mathrm{~min}$. After $90 \mathrm{~min}$, the flies were removed from respective tubes and segregated (equal number of male and female flies) into vials with (a) Trizolin for RNA extraction (10 flies each); (b) protein extraction buffer for catalase and superoxide dismutase (SOD) enzyme assays (20 flies each); (c) extraction buffer reduced GSH and oxidized glutathione (GSSG) assay (20 flies each); and (d) $0.154 \mathrm{M} \mathrm{KCl}$ for 2,2-diphenyl-1-picrylhydrazyl (DPPH) assay and lipid peroxidation assay (26 flies each). The results of the experiments were presented as a percent change of parameters in the test group flies, with respect to the flies that did not receive tap stress, for each

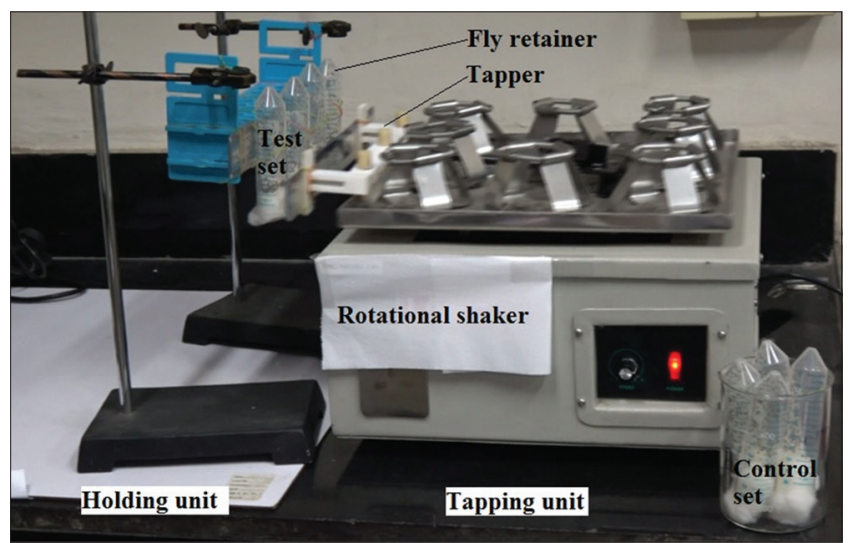

Fig. 1: Tap stress design of the instrumentation. The holding unit comprises two burette holding stands with attached tube rack for holding fly retainer tubes. Tapping unit constitutes a tapper that has been fixed to rotary shaker feeding regime. The variations in the response of the flies of different feeding regimes were ascertained.

\section{Catalase assay}

Catalase assay was performed by monitoring molecular breakdown of $\mathrm{H} 2 \mathrm{O} 2$ at $240 \mathrm{~nm}$ at pH 7 as per the method described by Aebi [18]. Adult flies were homogenized in protein extraction buffer containing $20 \mathrm{mM}$ tris-acetate buffer ( $\mathrm{pH} 7.8), 0.1 \%$ Triton X-100, and $1 \mathrm{mM}$ phenylmethanesulfonyl fluoride using micropestle homogenizer (Sigma Catalogue No.: Z359955-1EA). Protein values were measured using Bradford's assay. 1 unit of catalase activity is defined as the enzyme required for decomposing $1.0 \mu$ mole of $\mathrm{H} 2 \mathrm{O} 2 / \mathrm{min}$ at $\mathrm{pH} 7.0$ at $25^{\circ} \mathrm{C}$ and expressed as enzyme units.

\section{SOD assay}

SOD assay was performed by pyrogallol auto-oxidation inhibition method as described by Marklund and Marklund [19] with slight modifications. The inhibition of oxidation of pyrogallol was followed at $420 \mathrm{~nm}$ on a BioTek spectrophotometer (Model No.: EPOCH, Gen5). 1 unit of SOD activity was defined as the amount of enzyme that reduces the pyrogallol auto-oxidation by $50 \%$ at $\mathrm{pH} 8.5$ at $25^{\circ} \mathrm{C}$ and expressed as enzyme units.

\section{GSH measurement (total GSH and GSH: GSSG ratio)}

GSH and GSSG were measured using enzymatic recycling method referring to the protocol described by Rahman et al. (2006) [20]. The flies were homogenized in GSH extraction buffer containing $0.1 \mathrm{M}$ phosphate buffer with $5 \mathrm{mM}$ EDTA (pH 7.5), $6 \mathrm{mg} / \mathrm{ml}$ sulphosalicylic acid and $0.1 \%$ Triton X-100. Oxidation of GSH was carried out with 5 , 5'-dithio-bis-(2-nitro-benzoic acid) (DTNB) to form a yellow derivative, TNB, measurable at $412 \mathrm{~nm}$. The GSSG thus formed is recycled by GSH reductase enzyme in the presence of NADPH. The rate of formation of TNB in comparison to standards was correlated to find the concentration of the GSH and GSSG in the samples. The free GSH was derivatized with 2-vinylpyridine for accurate measurement of GSSG. The excess of 2-vinylpyridine was later neutralized with triethanolamine.

\section{DPPH scavenging assay}

The capacity of tissues to scavenge free radical was measured using DPPH free radical scavenging assay [21]. The adult flies were homogenized in $0.154 \mathrm{M} \mathrm{KCl}$ using micropestle homogenizer, and the whole body extract was used for the assay. The varying volumes $(20 \mu \mathrm{l}$, $40 \mu \mathrm{l}$, and $100 \mu \mathrm{l}$ ) of tissue extract were used for scavenging of DPPH. The amount of tissue required (in terms of mg of protein) for scavenging $50 \%$ DPPH was measured at $517 \mathrm{~nm}$ on BioTek spectrophotometer.

\section{Lipid peroxidation}

Lipid peroxidation was measured by thiobarbituric acid (TBA) reactive substances assay method $[22,23]$. The whole body extracts of adult flies were homogenized in $0.154 \mathrm{M} \mathrm{KCl}$, and it was then made to react with TBA reagent (containing $0.037 \mathrm{~g}$ TBA, 15\% trichloroacetic acid and $0.24 \mathrm{~N} \mathrm{HCl} / 10 \mathrm{ml}$ ). Reaction mixtures of the samples, as well as different concentration of standard malondialdehyde (MDA), were boiled for $15 \mathrm{~min}$, and the absorbance of the end product was measured at $532 \mathrm{~nm}$ on BioTek spectrophotometer. Concentration of MDA in the samples was estimated using the standard MDA plot.

\section{RT and qRT - polymerase chain reaction (PCR)}

The total cellular RNA was extracted by TRIZOL method as per manufacturer's instruction (Merck). Subsequently the cDNA was prepared using SD-prodigy cDNA synthesis kit (SD Fine Chem Ltd.). Primers for actin, cncC, hsp 70 and catalase (Table 1) were designed using the NCBI primer design tool.

Amplification of these genes was carried out with the help of PCR using the reaction setting as $94^{\circ} \mathrm{C}$ for $2 \mathrm{~min}$, repeated cycle of 25 cycles: Each of $94^{\circ} \mathrm{C}$ for $30 \mathrm{~s}, 62^{\circ} \mathrm{C}$ for $30 \mathrm{~s}$, and $72^{\circ} \mathrm{C}$ for $30 \mathrm{~s}$ with a final extension at $72^{\circ} \mathrm{C}$ for $5 \mathrm{~min}$. The products thus obtained were then run on $2 \%$ agarose gel. The gel was observed under UV trans-illuminator, and the images 
were captured in Uvitech system. The semi-quantitative estimation of changes in gene expression was carried out on the captured gel images using "ImageJ" software. Following this qRT PCR was carried out using Sybr based EVAGREEN (Biorad) on CFX96 real-time System (Biorad). The Ct values were analyzed for fold change in expression of genes using actin as an internal control. Data from both the experiments were compiled, and any mismatch data were repeated for qRT PCR to obtain accurate results. (Triplicates of real time PCR were not performed due to paucity of funds)

\section{Statistical analysis}

All the experiments were performed with a minimum of triplicates, and the statistical significance between two mean values was analyzed using Student's t-test. For comparing more than two means, analysis of variance (ANOVA) test was performed. ANOVA was followed by Bonferroni and Holm multiple comparison post-hoc analysis. For comparing other intergroup differences (between test groups) Tukey honestly significant difference (HSD) post-hoc method was performed. Throughout the manuscript, *and ${ }^{* *}$ represent holm inferences $\mathrm{p}<0.05$ and $\mathrm{p}<0.01$, respectively; while ${ }^{\#}$ and ${ }^{\# \#}$ represents Tukey HSD inference $\mathrm{p}<0.05$ and $\mathrm{p}<0.01$, respectively.

\section{RESULTS}

\section{Effect of tap stress on antioxidant enzymes}

SOD and catalase are the key enzymes in managing oxidative stress. The flies from control feeding regime subjected to the tap stress showed no significant changes in the SOD activity, in comparison to the flies not subjected to stress from this feeding regime. The flies from other feeding regimes also exhibited similar response and no prominent change in the SOD activity was detected. The percent change in the SOD activity in flies from various feeding regimes was found to be statistically non-significant (ANOVA $p=0.381239$ ). Similarly, the percent change in catalase activity in flies subjected to tap stress was also found to be insignificant in the flies of all feeding regimes tested (ANOVA $\mathrm{p}=0.648748$ ) (Table 2 and Fig. 2 ).

\section{Changes in free radical scavenging capacity}

The alteration in the free radical scavenging capacity in response to tap stress was monitored as the capacity to scavenge artificial DPPH free radicals in vitro (Table 2 and Fig. 3a). The percent change in the amount of tissue (proteins in the extract) required for scavenging $50 \%$ of DPPH free radical did not differ significantly between flies from ASC and $\mathrm{AB}$ feeding regimes compared to the response of flies from control feeding regime (ANOVA $p=0.003003$ ). However, a significant decrease in the scavenging capacity was observed in flies from the ASC feeding regime in comparison to the flies from $0.1 \% \mathrm{AB}$ feeding regime (Tukey HSD inference: $\mathrm{p}<0.01$ ). The significant ANOVA $p$-value was found to be only due to the differences in the response of flies from ASC and $0.1 \%$ $\mathrm{AB}$ feeding regimes.

When the total GSH contents and GSH: GSSG ratio in the flies from different feeding regimes and subjected to tap stress were compared with one another, a significant variation could be noticed (Table 2 and Fig. 4). In response to tap stress, the control flies showed about $34 \%$ decrease in total GSH content as compared to the control flies not subjected to tap stress. The flies from the ASC feeding regime, compared to control flies without tap stress, did not show any significant change in response to tap stress. On the contrary, the flies from $0.1 \% \mathrm{AB}$ to $0.5 \% \mathrm{AB}$ feeding regimes showed close to $36 \%$ increase in total GSH content in response to the stress. The percent change in total GSH content of flies from $0.1 \% \mathrm{AB}$ to $0.5 \% \mathrm{AB}$ feeding regimes, with respect to the flies from control feeding regime, was found to be statistically significant (Holm inference: $<0.01,<0.01$, respectively, with overall ANOVA $p=0.006345$ )

The GSH: GSSG ratio is another important indicator of stress. In general, the decrease in the ratio is observed with an increase in oxidative stress. In this regard, only flies from ASC feeding regime showed an increase in this ratio, while flies from other feeding regimes showed either no change or decrease in the ratio (ANOVA $p=0.008141$ ). Control flies were the most affected due to tap stress and the percent change in ratio was found to be statistically significant in comparison to flies from the ASC feeding regime (holm inference: $\mathrm{p}<0.01$ ). While no significant differences were observed between any other feeding groups.

\section{Lipid peroxidation}

No significant changes in the MDA contents were observed in the flies from control, $\mathrm{AB}$ and ASC feeding regimes due to tap stress (Table 2 and Fig. 3b). Furthermore, the percent change in the MDA content between the flies of different feeding regimes was found to be statistically insignificant (Overall ANOVA $\mathrm{p}=0.264733$ ).

\section{Transcriptional changes}

There have been changes in the extent of transcription of certain genes in flies from different feeding regimes subjected to tap stress (Fig. 5). Under the current experimental conditions, the flies from control and ASC feeding regimes showed a fairly similar expression of $\mathrm{cncC}$ transcription factor as well as catalase gene in comparison to the flies from their respective controls. However, these flies showed about half fold decrease in the hsp70 gene expression. On the contrary, flies from $0.1 \% \mathrm{AB}$ feeding regime showed about 2 -fold increase in the expression of cncC, hsp70 and catalase genes in response to the tap stress. Similarly, tap stress induced about 2.5-fold increase in these genes in flies from $0.5 \% \mathrm{AB}$ feeding regime.

Table 1: Genes and primers

\begin{tabular}{llll}
\hline Genes & Product size & Forward & Reverse \\
\hline Actin & $469 \mathrm{bp}$ & CGGCTCGGACAGTGATAGAC & CCGGTACCAAGTATCCTCGC \\
cncC & $147 \mathrm{bp}$ & AGCGCTAGGCTAAAGCAACA & GACAGTTAACGGGACGCTCT \\
hsp70 & $188 \mathrm{bp}$ & TTGACAACCGGCTAGTCACT & GGTGTAGAAGCTTGGCCCT \\
Catalase & $366 \mathrm{bp}$ & GAACTGCCCGTACAAGGTGA & GTCAGCATGCGACCGAAATC \\
\hline
\end{tabular}

cncC: Cap "n" collar C, hsp: Heat shock protein

Table 2: Percent changes in the oxidative parameters due to tap stress

\begin{tabular}{lllll}
\hline Parameters studied (percent change) & Control & ASC & $\mathbf{0 . 1 \%} \mathbf{A B}$ & $\mathbf{0 . 5 \%}$ AB \\
\hline SOD activity & $2.7 \pm 10.1$ & $-20.2 \pm 7.4$ & $16.6 \pm 13$ & $12.3 \pm 23.1$ \\
Catalase activity & $3.2 \pm 2.4$ & $4.5 \pm 3.9$ & $-0.6 \pm 2.7$ & $3.3 \pm 3.0$ \\
DPPH scavenging activity & $7.4 \pm 4.5$ & $18.4 \pm 4.3$ & $-5.6 \pm 2.8$ & $0.2 \pm 3.3$ \\
MDA content & $-4.0 \pm 2.6$ & $-8.4 \pm 3.3$ & $-0.7 \pm 3.1$ & $1.6 \pm 6.0$ \\
Total GSH & $-34.3 \pm 6.8$ & $-0.3 \pm 9.5$ & $34.2 \pm 20.0$ & $37.8 \pm 20.9$ \\
GSH: GSSG ratio & $-39.7 \pm 10.9$ & $36.1 \pm 15.4$ & $-16.6 \pm 20.0$ & $-23.0 \pm 12.9$ \\
\hline
\end{tabular}

ASC: Ascorbic acid, SOD: Superoxide dismutase, GSH: Glutathione, GSSG: oxidized glutathione, DPPH: 2,2-diphenyl-1-picrylhydrazyl, MDA: Malondialdehyde 


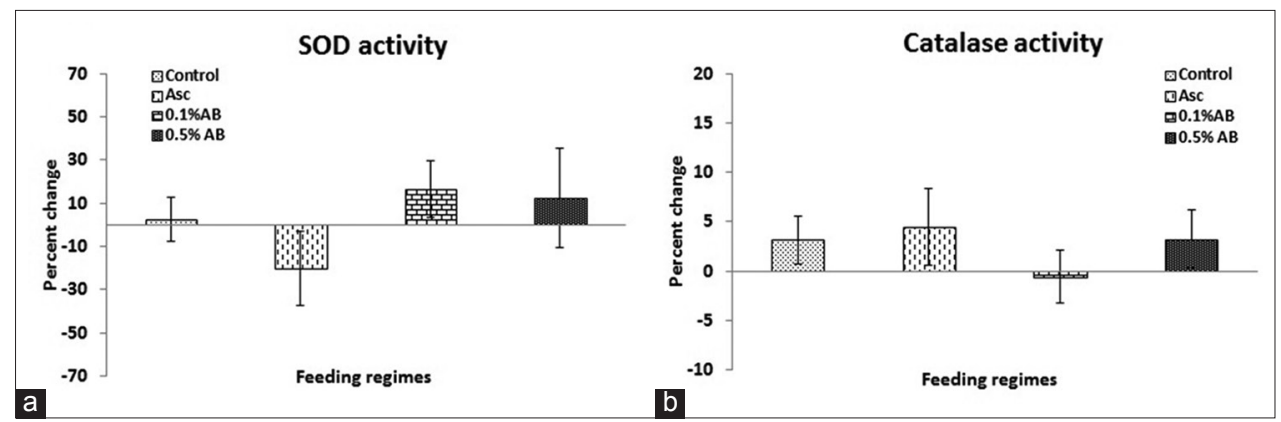

Fig. 2: Percent change in the activity of (a) superoxide dismutase enzyme, (b) catalase enzyme

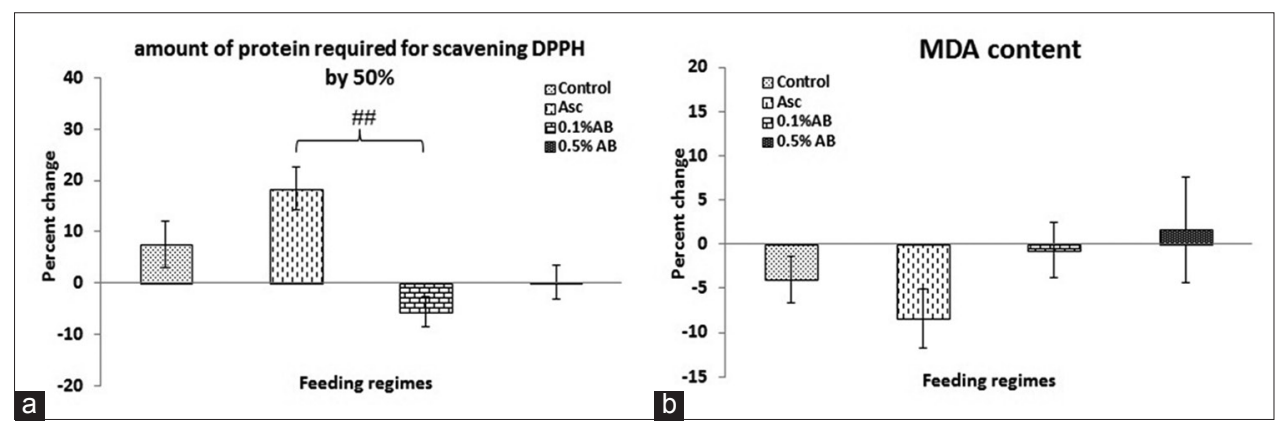

Fig. 3: Percent change in (a) amount of tissue required for 50\% 2,2-diphenyl-1-picrylhydrazyl scavenging. (b) Extent of lipid peroxidation (measured as total malondialdehyde content). ${ }^{\# \#}$ Represents Tukey honestly significant difference inference of $p<0.01$

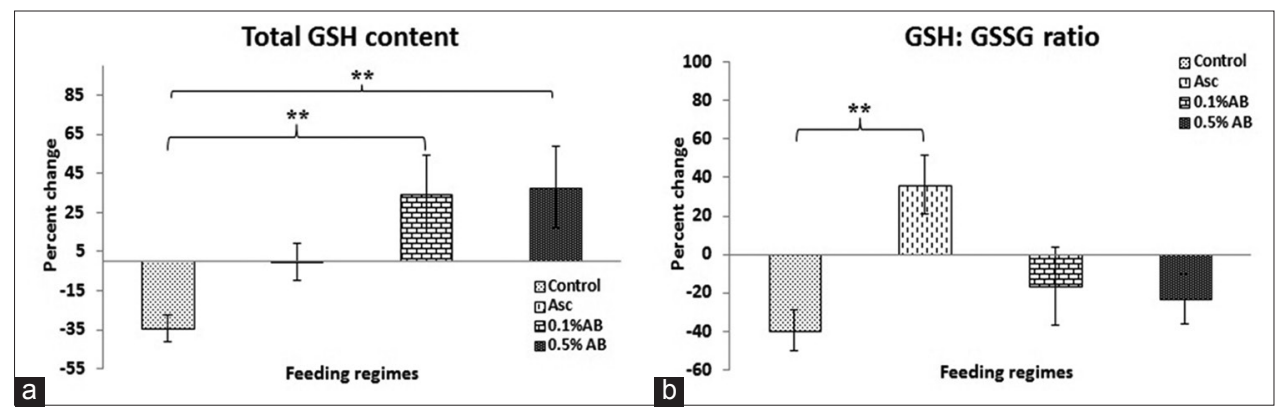

Fig. 4: Percent change in (a) total glutathione (GSH) content. (b) GSH: oxidised glutathione ratio (**represents Holm inference of $\mathbf{p}<\mathbf{0 . 0 1 )}$

\section{DISCUSSION}

The muscles related to flying and walking demand relatively higher amount of energy and are also the predominant producers of free radicals $[24,25]$. These free radicals can lead to the production of other reactive species such as reactive oxygen species and RNS. These reactive substances can subsequently interact with key biomolecules and could disrupt the cellular functions. Therefore, it is imperative to comprehend the stresses induced during activities related to muscles. Insects have been used as a model system for a wide range of physiological effects and results have been successfully extrapolated to other organisms [26,27]. Even after such wide applications, there is a scarcity of methods for inducing physical/exercise stress in insect models. Keeping this in mind, a method of tap stress in Drosophila insect model system has been developed. The negatively geotactic nature of these flies, in which they tend to climb/fly upward in an enclosed tube container, has been explored for this $[17,28]$. A gentle tap can bring these flies to the bottom of the tube following which flies again start to climb/fly upward in the tube. This process is repeated over and over at a certain time interval to simulate a condition of intense muscular exercise. Piazza et al. have demonstrated that this process mimics the exercise given to the rodents in a laboratory setting [29]. Meager requirements and the simplicity of the assembly for the tap stress used in the laboratory are some of the unique advantages of the method presented here.

After inducing continuous muscular activity through taps, the changes in the various oxidative parameters of Drosophila flies were explored. In addition, the efficacy of diet supplemented with ASC (a natural antioxidant) and $\mathrm{AB}$ (an ayurvedic preparation) in amelioration of the tap stress was also explored.

The SOD and catalase enzymes play an important role in the management of oxidative stress generated due to the accumulation of free radicals. The increase in the activity of these enzymes and also molecular expression enhance the capacity of an organism to manage oxidative stress and thus improves life expectancy [30,31]. Interestingly, due to tap stress, no significant changes in the activity of SOD and catalase enzyme have been observed in flies with or without any diet supplement of test compounds. However, at the transcription level, flies supplemented with $\mathrm{AB}$ show about 2 -fold increase in the catalase gene expression, though only a small decrease has been noticed in flies from the ASC feeding regime. Thus, feeding the flies with AB can provide a slightly better adaptive advantage in stress-induced through muscular activity. 


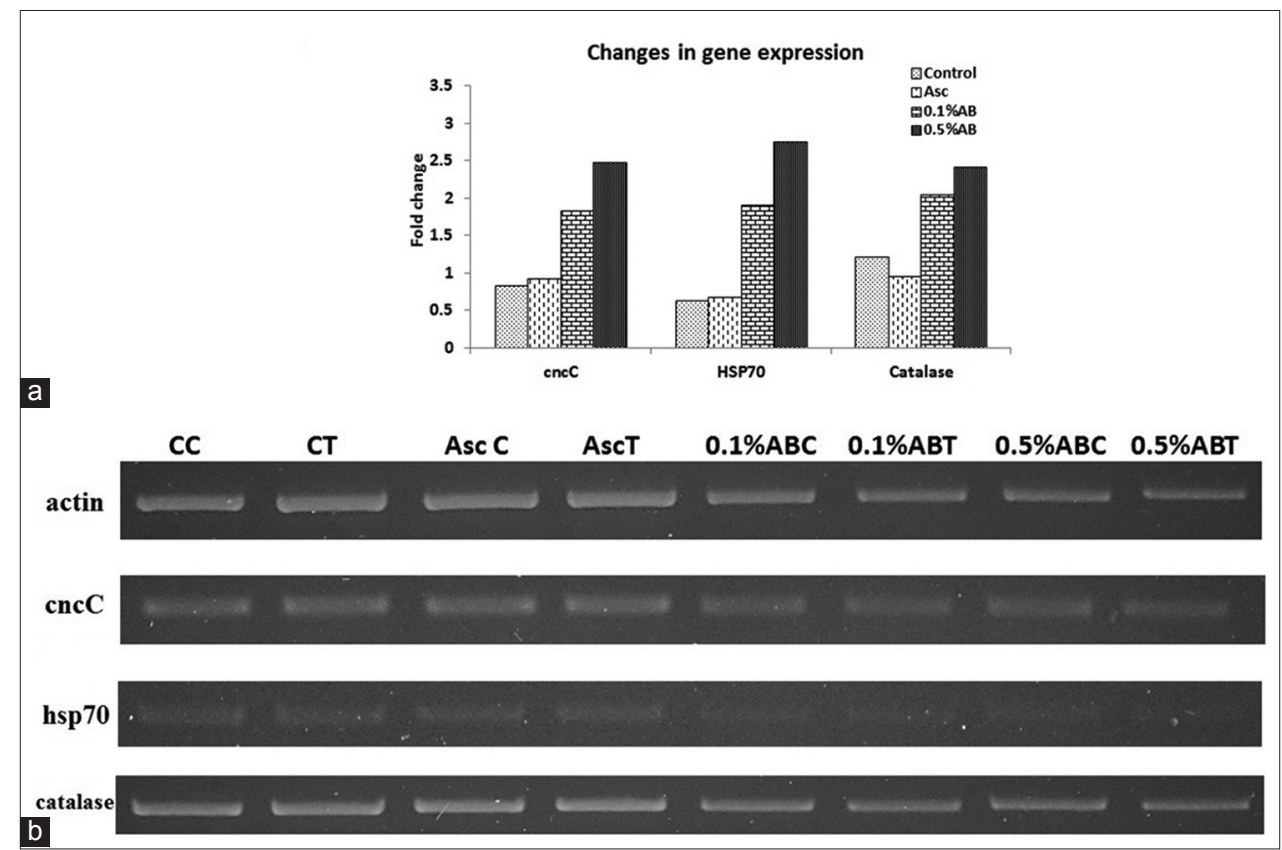

Fig. 5: Changes in the transcription of stress-related genes in response to tap stress (a) qRT-Polymerase chain reaction (PCR) results (b) RT PCR followed by electrophoresis on $2 \%$ agarose gel (later analyzed using "ImageJ" software for semi-quantitative data)

The other chemical defense against any stressful situation is generally mediated through non-catalytic components like GSH system [32,33]. The tap stress leads to a decrease in total GSH content as well as GSH: GSSG ratio in Drosophila flies from control feeding regime in comparison to their counterparts not subjected to tap stress. It suggests that these flies in response to tap stress likely to rely on GSH system as a primary defense. The flies from AB feeding regime, subjected to tap stress, exhibit an increase in the total GSH content without any significant change in the GSH: GSSG ratio is noticed. On the contrary, flies from ASC feeding regime respond to the tap stress with no change in the total GSH content while a significant increase in the GSH: GSSG ratio. These results suggest that supplementation of the diet with AB and ASC boosts the non-catalytic antioxidant machinery of Drosophila. These diet supplements can be directly involved in the management of oxidative stress or indirectly by inducing some other system, which has not been explored in the present investigation.

The general free radical scavenging capacity of flies has been indirectly measured through DPPH free radical scavenging assay. It suggests that the tap stress does not cause any significant difference in the overall free radical scavenging capacity of flies from control as well as AB feeding regimes. However, flies from ASC feeding regime show significant decrease in the free radical scavenging capacity. This is in contrast to the findings of the increase in the GSH: GSSG ratio, and therefore, it can be presumed that ASC may be boosting some alternate mechanism of managing exercise stress, yet to be explored.

Besides the catalase gene, other stress-related genes such as cncC and hsp70, through their products, play an important role in the management of various stresses [9,34]. In this regard, diet supplement of $A B$ seems to have a better protective role in countering the effect of tap stress. Flies from the $\mathrm{AB}$ feeding regime, at $0.1 \%$ as well as $0.5 \%$ concentration, show an increase in the expression of $\mathrm{cncC}$ transcription factor as well as hsp70 genes. Of these, $\mathrm{cncC}$ is the key regulator of oxidative stress, and its overexpression can relieve the organism of the stress [34]. The molecular chaperone hsp70 has a key role in maintaining the stability of various proteins required for cell survival, and therefore its overexpression has also been linked to the better resistance/tolerance to the induced stress [35].
Tap stress does not induce any significant increase in the lipid peroxidation level, and therefore it is safe to infer that limited exposure to tap stress can be managed very well through catalytic and noncatalytic components and no permanent structural damage is thus inflicted.

\section{CONCLUSION}

It is evident that the tap stress manifests its effect on various oxidative stress parameters in Drosophila flies. The non-catalytic antioxidant mechanism plays a key protective role during the exercise stress (Tap stress). The dietary supplement of $\mathrm{AB}$ seems to improve the antioxidant defense system of Drosophila flies. This has been mainly achieved through boosting of non-catalytic antioxidant mechanism as well as changes in the molecular expression of regulatory genes such as cncC and hsp70. Furthermore, the supplementation of ASC, to a certain extent, enhances the antioxidant defense system of the flies mediated mainly through non-catalytic antioxidant mechanism.

\section{ACKNOWLEDGMENT}

No special acknowledgements.

\section{REFERENCES}

1. Warburton DE, Nicol CW, Bredin SS. Prescribing exercise as preventive therapy. Can Med Assoc J 2006;174:961-74.

2. Halliwell B, Gutteridge JM. Free Radicals in Biology and Medicine. $5^{\text {th }}$ ed. Oxford: Oxford University Press; 2015.

3. Davison GW. Exercise and oxidative damage in nucleoid DNA quantified using single cell gel electrophoresis: Present and future application. Front Physiol 2016;7:249.

4. Novak CM, Burghardt PR, Levine JA. The use of a running wheel to measure activity in rodents: Relationship to energy balance, general activity, and reward. Neurosci Biobehav Rev 2012;36:1001-14.

5. Watson J. Oxidants, antioxidants and the current incurability of metastatic cancers. Open Biol 2013;3:120144.

6. Rahal A, Kumar A, Singh V, Yadav B, Tiwari R, Chakraborty S, et al. Oxidative stress, prooxidants, and antioxidants: The interplay. Biomed Res Int 2014;2014:761264.

7. Meister A. Selective modification of glutathione metabolism. Science 1983;220:472-7.

8. Menni C, Metrustry SJ, Mohney RP, Beevers S, Barratt B, Spector TD, et al. Circulating levels of antioxidant vitamins correlate with better 
lung function and reduced exposure to ambient pollution. Am J Respir Crit Care Med 2015;191:1203-7.

9. Silver JT, Noble EG. Regulation of survival gene hsp70. Cell Stress Chaperones 2012;17:1-9.

10. Brewer MS. Natural antioxidants: Sources, compounds, mechanisms of action, and potential applications. Compr Rev Food Sci Food Saf 2011;10:221-47.

11. Chand K, Rajeshwari, Hiremathad A, Singh M, Santos MA, Keri RS. A review on antioxidant potential of bioactive heterocycle benzofuran: Natural and synthetic derivatives. Pharmacol Rep 2017;69:281-95.

12. Rutkowski M, Grzegorczyk K. Adverse effects of antioxidative vitamins. Int J Occup Med Environ Health 2012;25:105-21.

13. Dueñas-García IE, Heres-Pulido ME, Arellano-Llamas MR, De la Cruz-Núñez J, Cisneros-Carrillo V, Palacios-López CS, et al. Lycopene, resveratrol, vitamin $\mathrm{C}$ and $\mathrm{FeSO} 4$ increase damage produced by pro-oxidant carcinogen 4-nitroquinoline-1-oxide in Drosophila melanogaster: Xenobiotic metabolism implications. Food Chem Toxicol 2017;103:233-45.

14. Massie HR, Aiello VR, Doherty TJ. Dietary vitamin C improves the survival of mice. Gerontology 1984;30:371-5.

15. Pallauf K, Bendall JK, Scheiermann C, Watschinger K, Hoffmann J, Roeder T, et al. Vitamin C and lifespan in model organisms. Food Chem Toxicol 2013;58:255-63.

16. Dwivedi V, Anandan EM, Mony RS, Muraleedharan TS, Valiathan MS, Mutsuddi $\mathrm{M}$, et al. In vivo effects of traditional ayurvedic formulations in Drosophila melanogaster model relate with therapeutic applications. PLoS One 2012;7:e37113.

17. Subedi RP, Vartak RR, Kale PG. Effect of abhrak bhasma on the physiology and behaviour of Drosophila melanogaster. Int J Adv Res 2017;5:1629-41.

18. Aebi HE. Catalase. In: Method of Enzymatic Analysis. Vol. 3. Germany, Weinheim, FL: VCH, Germany-Deerfield; 1983. p. 273-86.

19. Marklund S, Marklund G. Involvement of the superoxide anion radical in the autooxidation of pyrogallol and a convenient assay for superoxide dismutase. Eur J Biochem 1974;47:469-74.

20. Rahman I, Kode A, Biswas SK. Assay for quantitative determination of glutathione and glutathione disulfide levels using enzymatic recycling method. Nat Protoc 2006;1:3159-65.

21. Brand-williams W, Cuvelier ME, Berset C. Use of free radical method to evaluate antioxidant activity. Lebensm Wiss Technol 1995;28:25-30.

22. Zeb A, Ullah F. A simple spectrophotometric method for the determination of thiobarbituric acid reactive substances in fried fast foods. J Anal Methods Chem 2016;2016:9412767.

23. Devasagayam TP, Boloor KK, Ramasarma T. Methods for estimating lipid peroxidation: An analysis of merits and demerits. Indian $\mathrm{J}$ Biochem Biophys 2003;40:300-8.

24. Musarò A, Fulle S, Fanò G. Oxidative stress and muscle homeostasis. Curr Opin Clin Nutr Metab Care 2010;13:236-42.

25. Steinbacher P, Eckl P. Impact of oxidative stress on exercising skeletal muscle. Biomolecules 2015;5:356-77.

26. Jennings BH. Drosophila-a versatile model in biology and medicine. Mater Today 2011;14:190-5.

27. Beckingham KM, Armstrong JD, Texada MJ, Munjaal R, Baker DA. Drosophila melanogaster - the model organism of choice for the complex biology of multi-cellular organisms. Gravit Space Biol Bull 2005; 18:17-29.

28. Nichols CD, Becnel J, Pandey UB. Methods to assay Drosophila behavior. J Vis Exp 2012; pii: 3795.

29. Piazza N, Gosangi B, Devilla S, Arking R, Wessells R. Exercisetraining in young Drosophila melanogaster reduces age-related decline in mobility and cardiac performance. PLoS One 2009;4:e5886.

30. Le Bourg E. Oxidative stress, aging and longevity in Drosophila melanogaster. FEBS Lett 2001;498:183-6.

31. Durga M, Nathiya S, Devasena T. In vitro evaluation of cytotoxicity, oxidative stress, DNA damage and inflammation induced by diesel exhaust particles in human a549 lung cells and murine raw 264.7 macrophages. Int J Pharm Pharm Sci 2014;6:105-10.

32. Noctor G, Foyer CH. Ascorbate and glutathione: Keeping active oxygen under control. Annu Rev Plant Physiol Plant Mol Biol 1998;49:249-79.

33. Dasari P, Anandamurali R, Nayak P. Effect of tocotrienol pretreatment on ex vivo superoxide and peroxide handling capacities (sphe) of rat serum and brain. Int J Pharm Pharm Sci 2017;9:116-22.

34. Bryan HK, Olayanju A, Goldring CE, Park BK. The Nrf2 cell defence pathway: Keap1-dependent and-independent mechanisms of regulation. Biochem Pharmacol 2013;85:705-17

35. Doganlar O, Doganlar ZB. Responses of antioxidant enzymes and heat shock proteins in Drosophila to treatment with a pesticide mixture. Arch Biol Sci 2015;67:869-76. 